\title{
GENERAL THRUST SURFACE OF MASONRY DOMES
}

\author{
ISTVÁN SAJTOS ${ }^{1 *}$, ORSOLYA GÁSPÁR ${ }^{2}$ AND ANDRÁS Á. SIPOS ${ }^{3}$ \\ 1,2,3 BME Budapest University of Technology and Economics \\ Department of Mechanics, Materials and Structures \\ H-1111 Budapest, Müegytem rkp 3., Hungary \\ e-mail: ${ }^{1}$ sajtos@szt.bme.hu, www.szt.bme.hu (*corresponding author) \\ email: ${ }^{2}$ gaspar@szt.bme.hu, ${ }^{3}$ siposa@eik.bme.hu, www.szt.bme.hu
}

Keywords: Masonry dome, Thrust surface, Catenary-type membrane surface, Funicular-type membrane surface, membrane shell

\begin{abstract}
Masonry domes are shell-like structures with a no-tension type material behavior [1]. The dome geometry, material behavior and the type of the loading define how the dome balances the load. It is known and proved that the dome could balance the load only by forces, without bending moment but cracks may appear since the material does not resist tension. The surface where the balancing forces are acting is called the thrust surface. The paper introduces the idea of the general thrust surface. It is such a balancing surface where the forces are not acting in the tangent plane of the thrust surface and otherwise it is moment free. A method is shown how to find the general thrust surface for a cracked spherical masonry dome. Numerical example illustrates the usefulness and effectiveness of the proposed method to determine the general thrust surface of a spherical dome when radial stereotomy is considered. By the help of the proposed model the safety of the more than 350 years old, cracked dome of Gol Gumbaz, India can be proofed.
\end{abstract}

\section{INTRODUCTION}

Masonry domes are shell-like structures with a no-tension type material behaviour [1]. The dome geometry, material behaviour and the type of the loading define how the dome balances the load. It is known and proved that the masonry dome could balance the load only by forces, without bending moment but cracks may/will appear since the material does not resist tension. The surface where the balancing forces are acting is called the thrust surface. Generally, this is not coincided by the mid-surface of the dome.

If the balancing forces are acting in the tangent plane of the thrust surface than the thrust surface is called catenary-type membrane/thrust surface. It is analogous to the envelope of resultant forces in case of masonry arches. If the membrane/thrust surface coincides with the mid-surface of the dome, then the dome is a funicular-type shell, i.e. a membrane shell. Otherwise, the masonry dome is safe if the thrust surface is located within the thickness of the dome, nevertheless cracks might form.

The thrust surfaces, mentioned above, can be examined and determined by e.g. thrust network analysis (TNA) [2, 11, 12] or by solving Pucher's equation for membrane shells, that provides the corresponding stress function $[3,4]$. If the dome cracks, then the thrust surface 
may still be approximated by the series of thrust lines that correspond to the modified model of the cracked dome, i.e. a series of orange-slice arches [1].

It is possible to find a moment-free surface (i.e. thrust surface) to arbitrary dome geometry and loads. However, depending on the stereotomy of the dome, it is not necessarily a membrane surface. This situation is analogous to the general relation between the resultant force vector and the thrust line in the masonry arch [5]. The term general thrust surface is introduced to label such a moment-free surface.

The present paper introduces a method to determine the general thrust surface for a spherical dome geometry for radial stereotomy. The load is defined relative to the mid surface of the dome.

Despite the rich literature investigating the phenomena's 2D equivalent (i.e. effect of stereotomy on the thrust line of masonry arches), to the authors knowledge the presented method is a novel approach in the analysis of domes. It may be shown, that both the catenarytype and the funicular-type membrane/thrust surfaces are special cases of the general thrust surface.

No-tension material behavior and cracks in particular could lead to a general thrust surface. Numerical example illustrates the usefulness and effectiveness of the proposed method to determine the general thrust surface of a spherical dome.

\section{GENERAL DESCRIPTION OF THE PROBLEM}

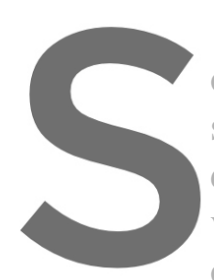

Spherical masonry

of the architectural he

structural point of view

direction for gravity

variation. However, this

of the dome [6].
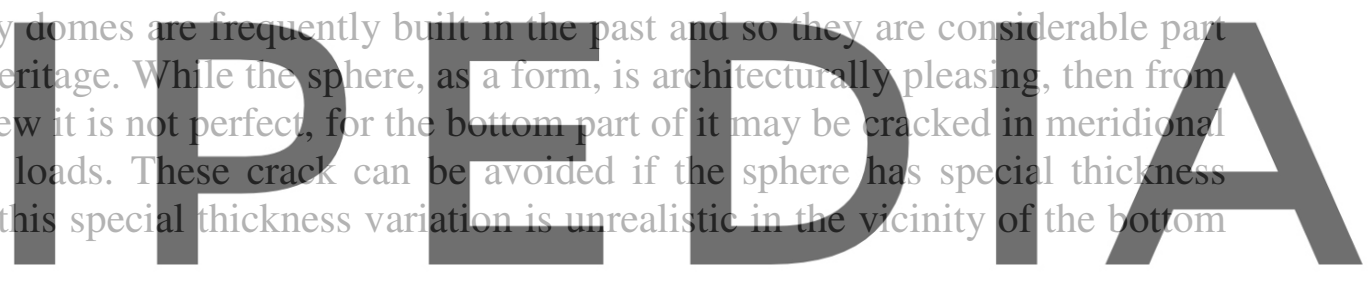

In case of real domes, it is a general experience that the dome is cracked in meridional

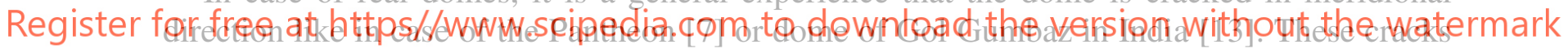

may be caused by the self-weight or other effects like temperature changing. Independently of

the real cause the main question is if the dome is safe in cracked state or not. Obviously the other important question could be how the cracks are developed due to certain loading considering the real, discrete nature of the cracks.

Now our purpose is to examine if a meridional cracked dome could be in equilibrium for its self-weight. We are looking for a thrust surface which provide the possibility to check the safety of the cracked dome. If the thrust surface is enclosed by the thickness of the dome than the equilibrium is possible.

The model considers the real state of dome such that the top cap part is not cracked, only the bottom one, Fig. 1 a.

Assumptions:

- The dome has hemispherical mid-surface and it is loaded by its self-weight.

- It is a masonry dome, made of no-tension material i.e. cracks for tension,

- The top, cap part of the dome is not cracked. Its behavior may be described by the membrane state of a spherical shell.

- The bottom part is cracked in meridional direction. The cracks are through cracks 
and it is assumed that they are so dense that no any internal force can develop in the circumferential direction Fig. 1b. Its behavior may be described by the bending theory of shells.

- The top and bottom parts are jointed along a circumferential circle at the top end of the cracks. The crack free cap defines the jointing conditions.

- The bottom edge support can resist both vertical and horizontal forces even when they are eccentric i.e. when bending moment is also acting there.

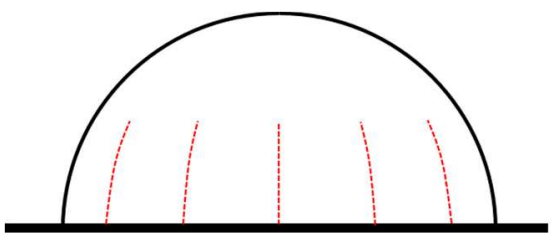

a)

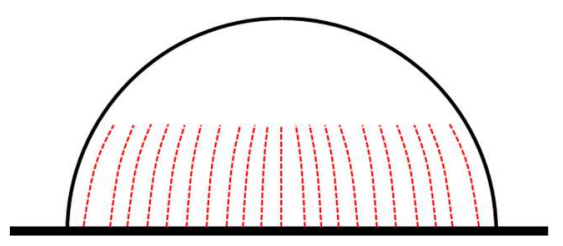

b)

\section{MASONRY DOME WITH CRACKS}

The two parts of the masonry dome, the cap and the cracked bottom part has different model corresponding to the different states. The cap is assumed to behave as a membrane shell which is under compression in both, meridional and circumferential, direction too, i.e. it is crack free. The model of the bottor the internal forces in the

The solutions for the

known in advance so it chapter 3.4 .
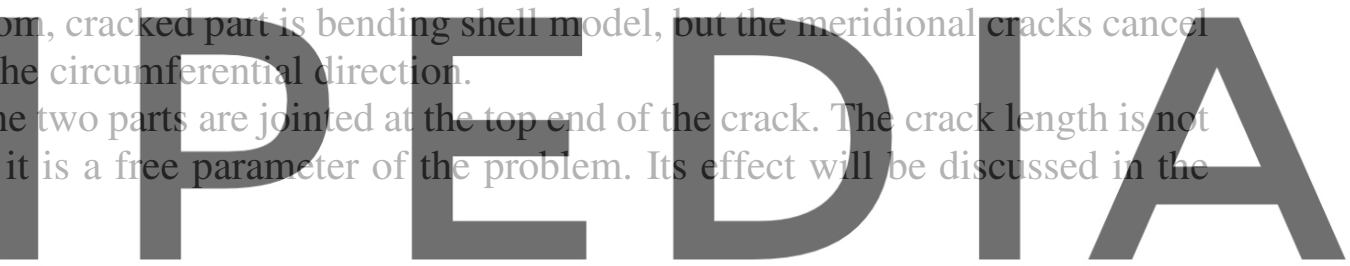

Register for free at https//www.scipedia.com to download the version without the watermark

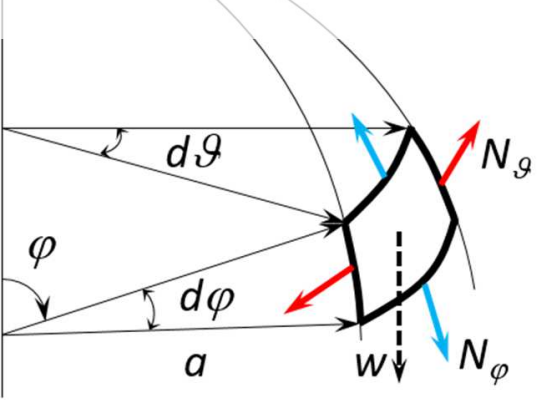

Figure 2: Membrane stet of the cap of the dome

\subsection{Solution for the cap of the dome}

The cap of the dome is in membrane stress state. The problem is rotationally symmetric as the self-weight as a load is also that kind. There are only two membrane normal forces to balance the load in each, meridional and circumferential, direction, Fig. 2. The equilibrium 
equations and its solutions for self-weight is well known in the literature, [8, 9, 10].

It is characteristics for the solution that there is circumferential tension below the so called neutral angle $\left(\varphi_{0}=51,82^{\circ}\right)$, while the cap part is under compression in both direction, Fig. 3 .

So there is a possibility to develop a through, meridional cracks due to circumferential tension even for self-weight. Corresponding to the no-tension material assumption the cracks run up to the neutral angle. Obviously for a real masonry dome material the crack should stop below the neutral angle depending on the tensile strength of the dome material. Otherwise these self-weight caused cracks may propagate further due to other effects like for example temperature changing and traffic caused vibration. Consequently, the cracks may end below or above of the neutral level independently if the self-weight alone could cause it.

That is why it is important to examine and discuss if the cracked dome is in equilibrium in cracked state for any length of the crack.

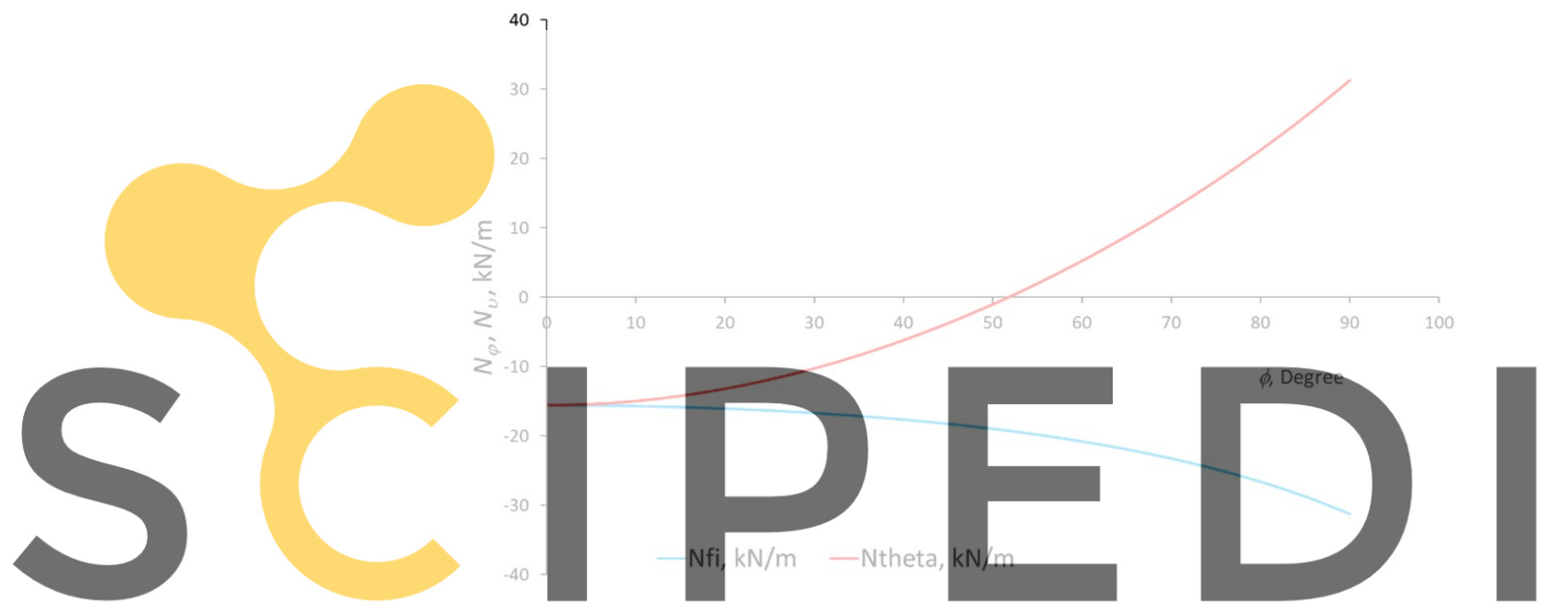

Figure 3: Membrane forces of the dome. $a=5 \mathrm{~m}, w=6,25 \mathrm{kN} / \mathrm{m}^{2}, t=38 \mathrm{~cm}$.

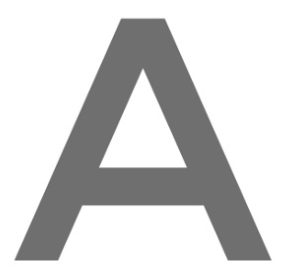

Register for free at https//www.scipedia.com to download the version without the watermark 3.2 Solution for the bottom, cracked part of the dome

The bottom, cracked part is considered as a bending shell but the meridional, through cracks are so dense that no circumferential internal forces are developed, i.e. there is no resistance into circumferential direction, Fig. 1 and 4. (This is a kind of approximate, "smeared crack" model, although typically there are only $8-16$ discrete cracks in real domes.) However, the bending is effective in the meridional direction and the rotational symmetry of the problem is not altered.

The equilibrium equations of the cracked dome according to the rotationally symmetric bending shell theory are, $[8,10]$ :

$$
\begin{gathered}
\frac{d}{d \varphi}\left(a \sin \varphi N_{\varphi}\right)-a \sin \varphi Q_{\varphi}+p_{\varphi} a^{2} \sin \varphi=0, \\
a \sin \varphi N_{\varphi}+\frac{d}{d \varphi}\left(a \sin \varphi Q_{\varphi}\right)+p_{r} a^{2} \sin \varphi=0, \\
\frac{d}{d \varphi}\left(a \sin \varphi M_{\varphi}\right)-a^{2} \sin \varphi Q_{\varphi}=0 .
\end{gathered}
$$

The equilibrium equation system can be solved without any need of geometrical and 
constitutive equation, i.e. the cracked dome part as a bending shell is statically determinate.

A closed form solution can be given analytically for self-weight $\left(w, \mathrm{kN} / \mathrm{m}^{2}\right)$ which is determined by the thickness variation $\left(t_{(\varphi)}, \mathrm{cm}\right)$ and the density of the material of the dome.

For uniform thickness $(t)$ and so for constant self-weight $(w)$, which is the worst case in that sense that the thickness variation is advantageous, the solution is:

$$
\begin{gathered}
a \sin \varphi N_{\varphi}=-C_{1} \sin \varphi+C_{2} \cos \varphi+\frac{1}{2} w a^{2} \sin 2 \varphi, \\
a \sin \varphi Q_{\varphi}=-C_{1} \sin \varphi-C_{2} \cos \varphi+w a^{2} \cos ^{2} \varphi, \\
a \sin \varphi M_{\varphi}=-C_{1} a \sin \varphi+C_{2} a \cos \varphi+w a^{3}\left(\frac{\varphi}{2}+\frac{1}{4} \sin 2 \varphi\right)+C_{3} .
\end{gathered}
$$

The $C_{i}$-s are integration constants and can be found from the static or natural boundary conditions provided by the cap part of the dome at the top end of the meridional cracks.

For other thickness variations the solutions from (1-3) equations can be found in a similar
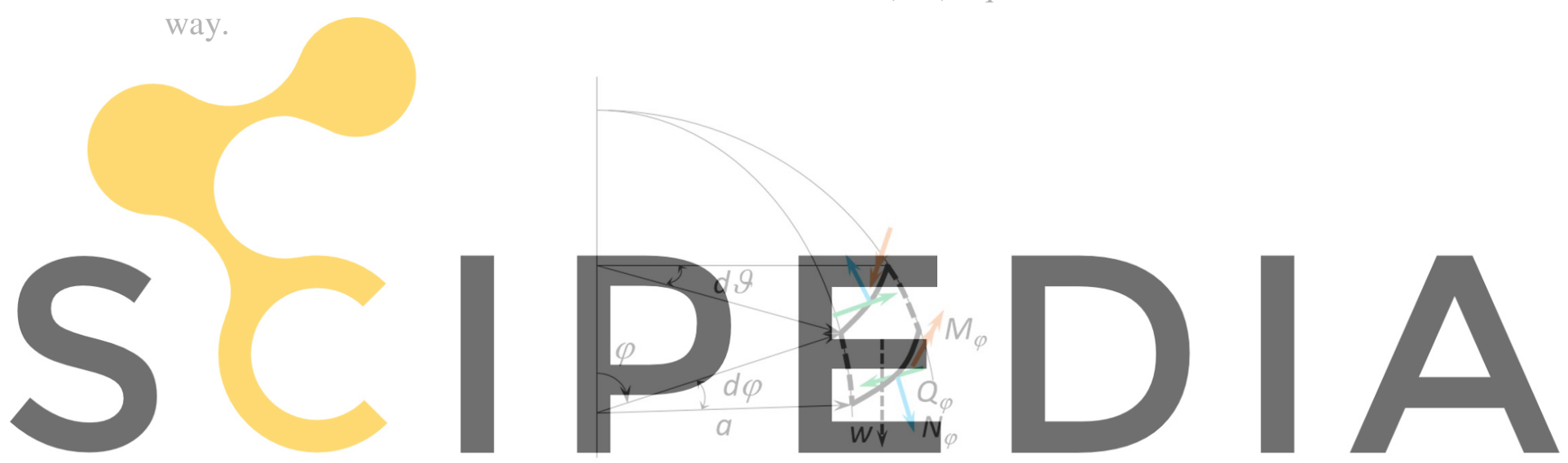

Register for free at https//Figure 4: Bending state of the cracked bottom part of the dome Figure 4: Bending state of the cracked bottom part of the dome
WWW.Scipedia.com to download the version without the watermark

\subsection{Jointing the solutions, the effect of crack length on the internal forces}

The solution for the cap at the end of the crack gives the boundary conditions for the cracked part. For a chosen crack length $\left(\varphi=\varphi_{0}\right)$ the internal forces are determined by the membrane solution. Namely the internal forces of the cracked part at the end of the crack, where $\varphi=\varphi_{0}$ are: $N_{\varphi\left(\varphi_{0}\right)}=N_{\varphi 0}, Q_{\varphi\left(\varphi_{0}\right)}=0$, and $M_{\varphi\left(\varphi_{0}\right)}=0$, where $N_{\varphi 0}$ is the membrane meridional force at $\varphi=\varphi_{0}$.

As it was said earlier the length of the crack, characterized by $\varphi_{0}$, is a parameter of the problem. Keeping in mind that we assumed no tension material behavior the crack end is at the neutral angle. Considering real material behavior with finite tensile strength the crack ends below the neutral level. However due to other effects than self-weight the crack may propagate above the neutral level and the dome must be in equilibrium even in this case too.

Some numerical results can be seen on Fig. 5 considering all these possibilities. Fig. 5c shows such a case when the crack is longer than what the no-tension case defines. Fig.5b is for the no-tension solution and the Fig. 5a shows the results for finite tensile strength material.

It is a general characteristic of each that the meridional force is not changed considerably for 
the cracked part. This is due to that the bending shear force is not too large and it is not really effective to balance the load. The meridional bending moment is not too large and it will determine the location of the thrust surface. The transition between the cap and cracked part is "smooth" considering the meridional-, shear force and bending moment. However, the circumferential force has jump at the jointing circle which is a crude estimation of the real behavior.

The connection between the two dome parts in reality is not along a circumferential circle but it is rather a transition zone which is not considered here in the proposed model.

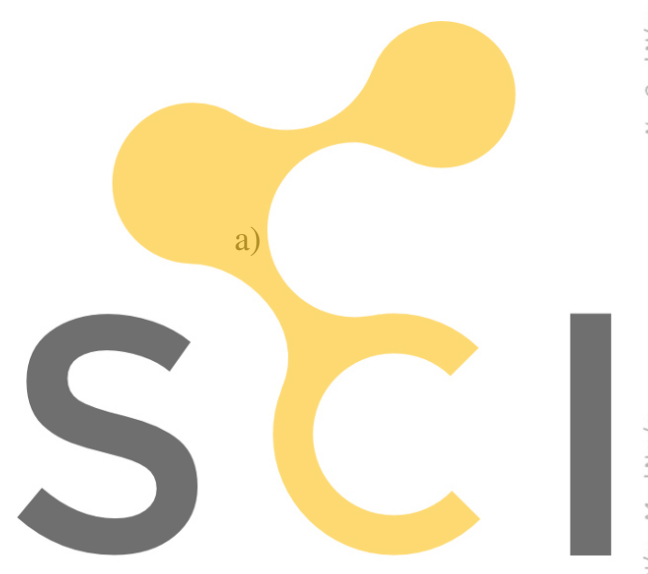

Register for free at https//wwwiscipedia.com to do

b)
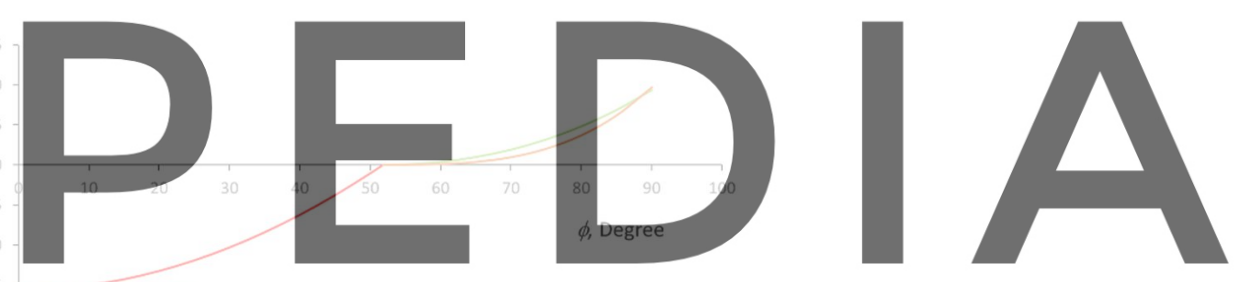

$--\mathrm{Nfi}, \mathrm{crack}, \mathrm{kN} / \mathrm{m}$

$-\mathrm{Mfi}, \mathrm{crack}, \mathrm{kNm} / \mathrm{m}$

c)

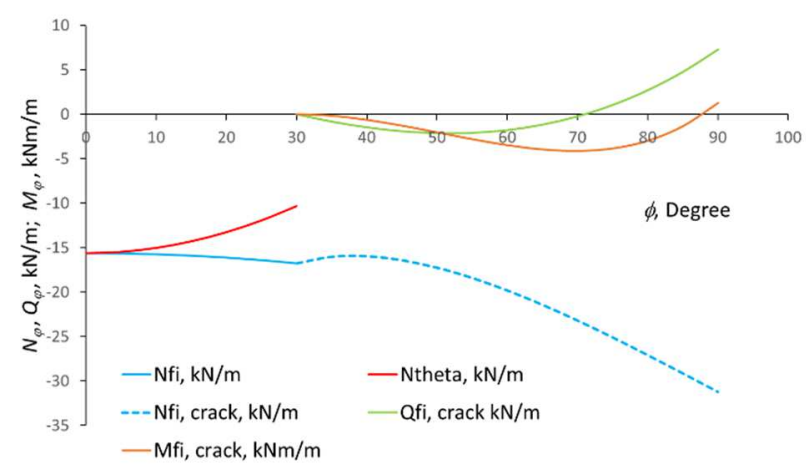

Figure 5: Internal forces of the cracked dome for different crack lengths. a) Crack length is $\varphi=70^{\circ}$, b) Crack length is at the neutral angle $\varphi=51,82^{\circ}$, c) Crack length is $\varphi=30^{\circ} . a=5 \mathrm{~m}, w=6,25 \mathrm{kN} / \mathrm{m}^{2}, t=38 \mathrm{~cm}$. 


\subsection{Thrust surface of the cracked dome}

The thrust line is a commonly used idea and object to examine the safety of masonry arches. The thrust surface is the 3D form of that, and can be understood as such a surface where the resultants of the balancing forces are acting i.e. it is a moment free surface, where only forces are acting. The masonry dome, with no-tension material, is in equilibrium if the thrust surface is inside the thickness of the dome.

Three kind of thrust surface can be distinguished similarly to the thrust lines. If the forces are acting in the tangent plane of the thrust surface than it is called catenary-type membrane/thrust surface, Fig. 6a. It is analogous to the envelope of resultant forces in case of masonry arches. If the thrust surface is coincided by the mid surface of the dome and the forces are acting in the tangent plane of the mid surface, then the dome is a funicular-type shell, with funicular-type membrane/thrust surface, Fig. 6b, i.e. a membrane shell. If the thrust surface is not coincided by the mid surface of the dome and the forces are not acting in its tangent plane, Fig. 6c, then the thrust surface is called general thrust surface.

The shape, location and the type of the thrust surface is influenced by the stereotomy of the dome, i.e. the bonding pattern of the dome masonry. Now we consider only one stereotomy, namely the radial one defined by the polar coordinate system used to give the equilibrium equations of different part of the dome.
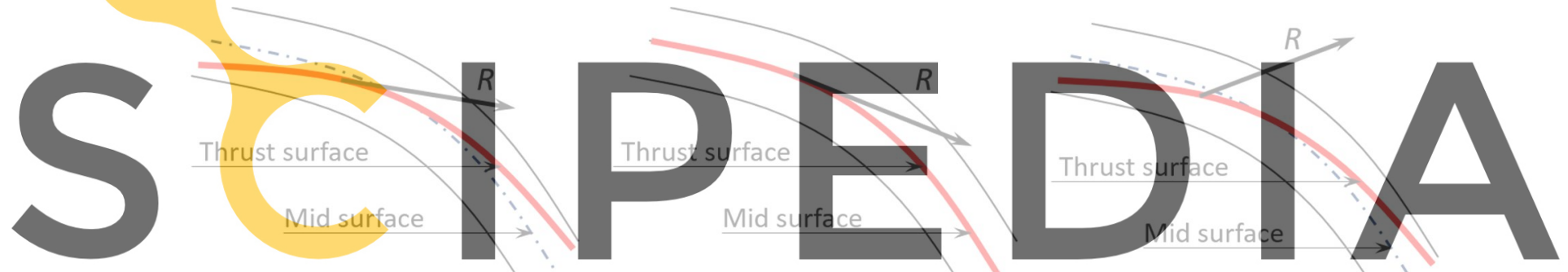

Figure 6: Types of thrust surfaces. a) catenary-type thrust surface, b) funicular-type thrust surface.

c) general thrust surface,

Since the cap of the dome is assumed to behave as a membrane shell its thrust surface is a catenary-type thrust surface.

For the cracked part, the thrust surface can be constructed as an eccentricity surface defined by the meridional normal force and bending moment, considering radial cross-sections defined by the polar coordinate-system, Fig. 7. It is a general thrust surface because the resultant of the meridional shear- and normal force is not on the tangent plane of the thrust surface, although it is very close to that.

The Fig. 7 and 8 show the meridional section of the thrust surface for different crack length. It can be seen that (for the assumed dome thickness) the worst crack length is when the crack goes up to the neutral angle. In both other cases when the crack is shorter, or enforced to be longer than the neutral angle is more advantageous in that sense that there is a possibility of the equilibrium for self-weight in cracked state. 


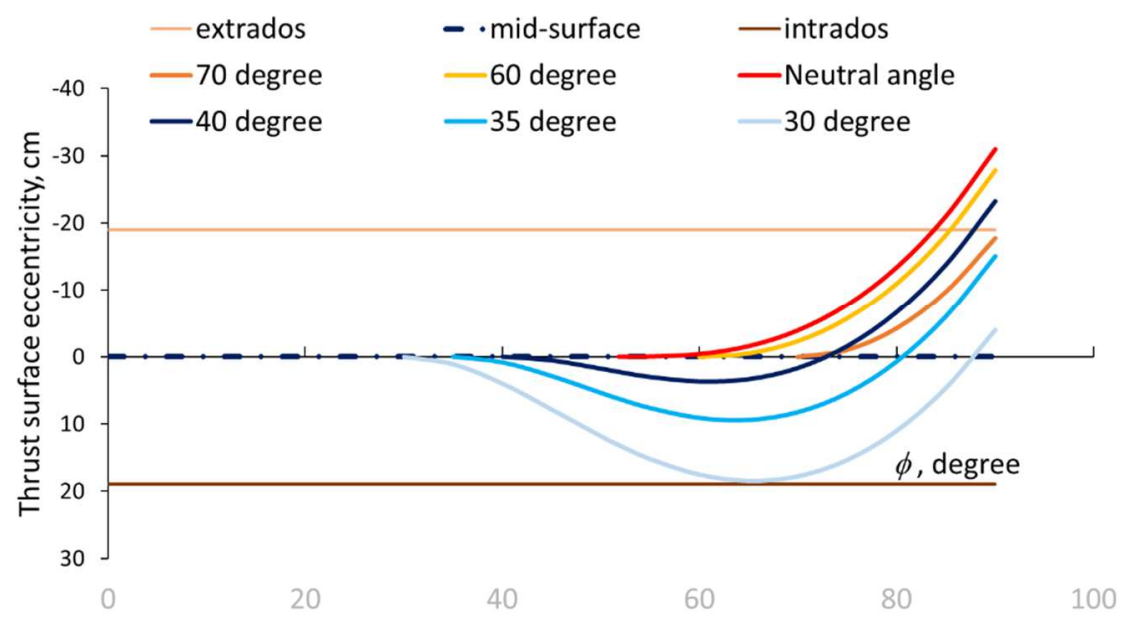

Figure 7: Meridional section of the general thrust surface of the dome for different crack lengths, the thrust surface eccentricity. $\left(R=5 \mathrm{~m}, t=38 \mathrm{~cm}, w=6,25 \frac{\mathrm{kN}}{\mathrm{m}^{2}}\right)$
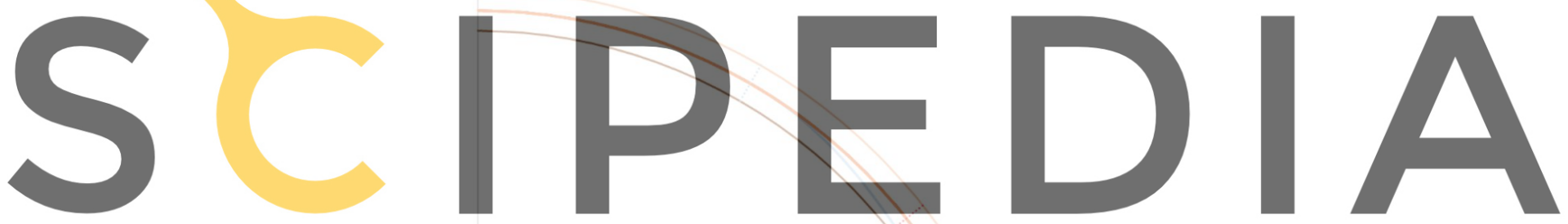

Register for free at https//www.scipedia.com to download the version without the watermark
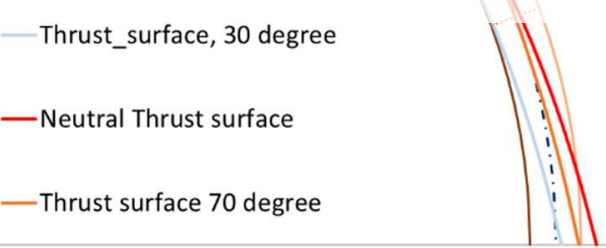

Figure 8: Meridional section of the general thrust surface of the dome for different crack lengths.

$$
\left(R=5 \mathrm{~m}, t=38 \mathrm{~cm}, w=6,25 \frac{\mathrm{kN}}{\mathrm{m}^{2}}\right)
$$

Considering the particular numerical example (Fig. 7 and 8) it may be concluded that the dome is safer than the masonry arch with the same geometry since the development of a (rotational) collapse mechanism has less probability. This is based on that thought (maybe speculation) that if the dome material has tensile strength the crack length is under the neutral level resulting smaller eccentricity at the support. If the eccentricity reaches the extrados i.e. a "plastic" hinge develops at the support, then the crack must move toward the neutral angle. 
However, this would increase the eccentricity at the support which is not possible. The only probable possibility that an unstable crack propagation occurs and the crack ends above the neutral angle. This could result an equilibrium state for the dome but there is a possibility to develop another circumferential plastic hinge on the intrados. Nevertheless, this is not probable since only very long cracks make this possibility. Shorter, but ended above neutral level cracks will even close the circumferential plastic hinge crack at the support. A third circumferential plastic hinge would be required to the collapse of the dome which cannot be developed in any case due to self-weight, according to this model.

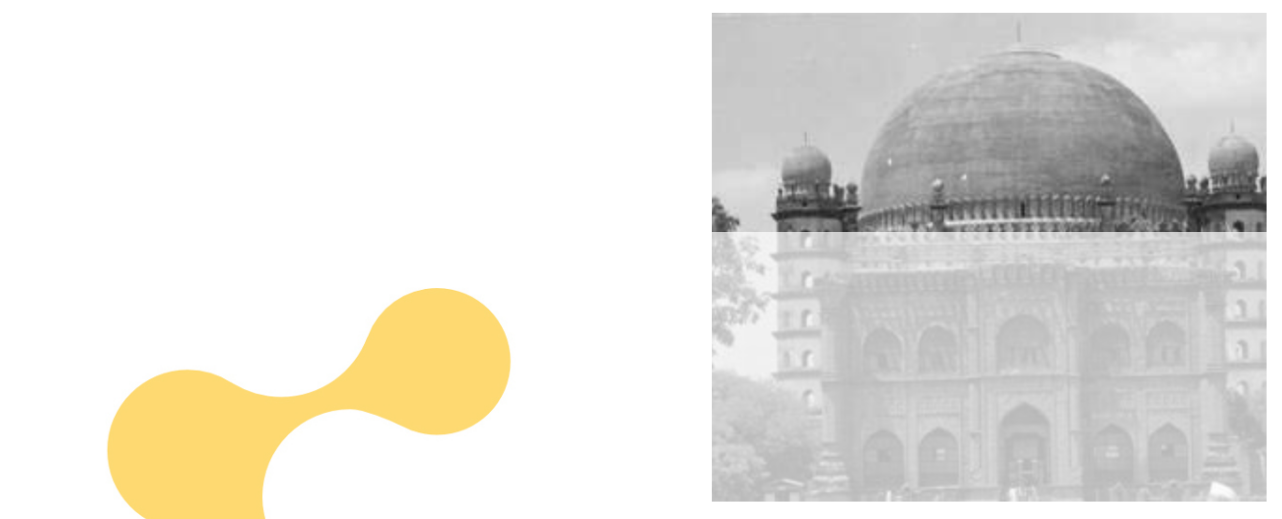

Figure 9: The building and the dome of Gol Gumbaz, India, Bijapur [13]

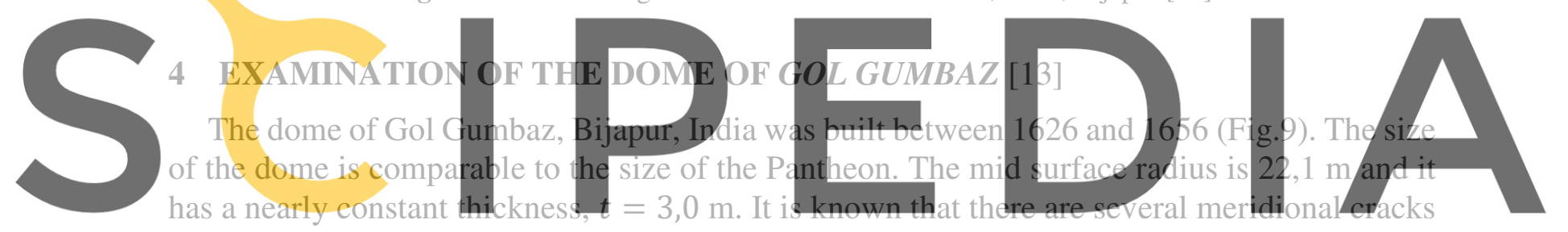

on the dome. The cracks end at $4-10 \mathrm{~m}$ above the terrace level, which is around the springing

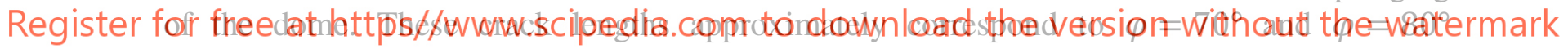
meridional angles, that means the cracks end below the neutral level of the dome according to the membrane theory. This indicates that the tensile strength of the dome material is effective.

The dome was repaired in 1936, after 280 years of construction, certainly having been in cracked state.

The self-weight of the dome is considered to be $60 \frac{\mathrm{kN}}{\mathrm{m}^{2}}$ [13]. The examination of the dome with the given data shows that the experienced cracks result safe equilibrium state for the dome.

Fig. 10. shows the thrust surface eccentricity for the experienced crack lengths. Otherwise Fig. 11. shows the corresponding thrust surfaces. For the shorter cracks the eccentricity is small enough that the dome wall is not cracked in hoop direction. It is suspected that for the longer crack there might be some cracks in hoop direction on the intrados about the springing.

The normal and shear stresses are acceptable and realistic for both crack lengths (see Table 1.) Although there is no information about the strength of the masonry material of the dome it is thought that the masonry made with lime mortar mixed with basalt gravels could easily have at least that strength which is in Table 1.

The calculation clearly proofs the long term experience, that the dome of Gol Gumbaz is safely standing in equilibrium state with the existing meridional cracks. 


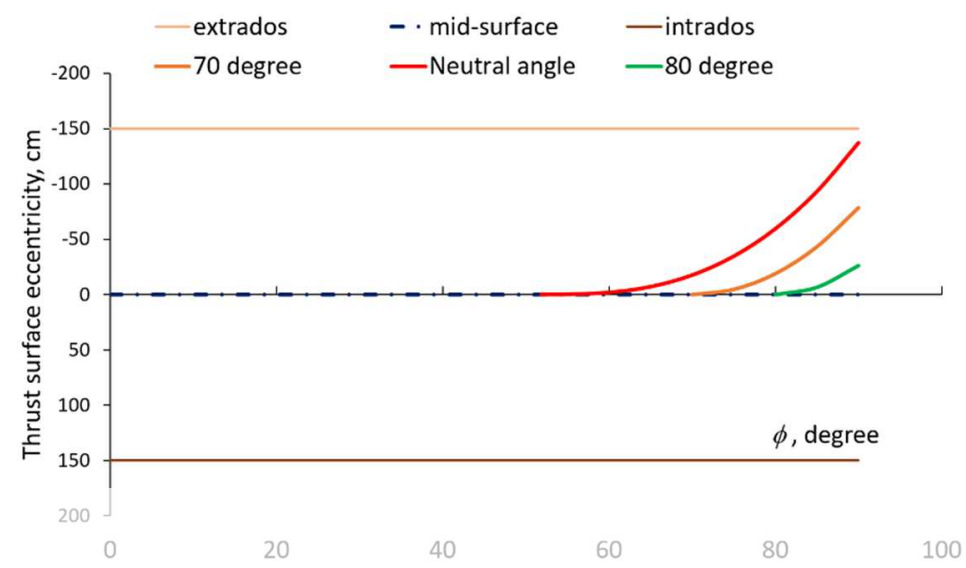

Figure 10: Meridional section of the general thrust surface of the dome of Gol Gumbaz for different crack lengths, the thrust surface eccentricity. $\left(R=22,1 \mathrm{~m}, t=300 \mathrm{~cm}, w=60 \frac{\mathrm{kN}}{\mathrm{m}^{2}}\right)$
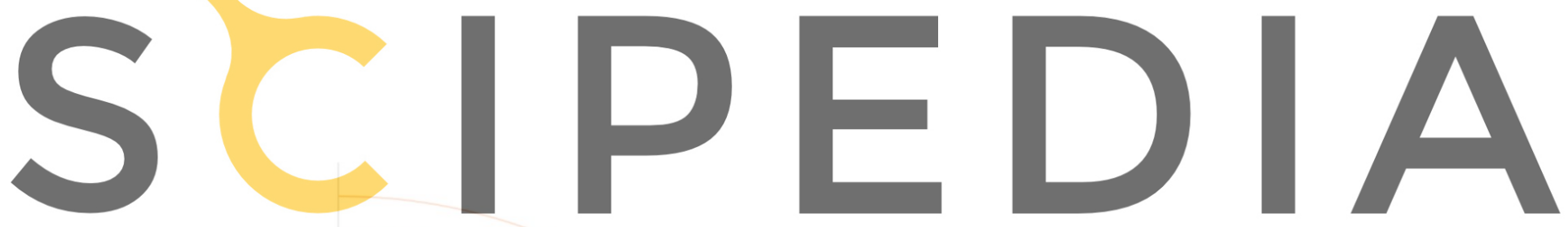

Register for free at https//www.scipedia.com to download the version without the watermark

- Neutral Thrust surface
- Thrust surface 70 degree
—Thrust surface 80 degree

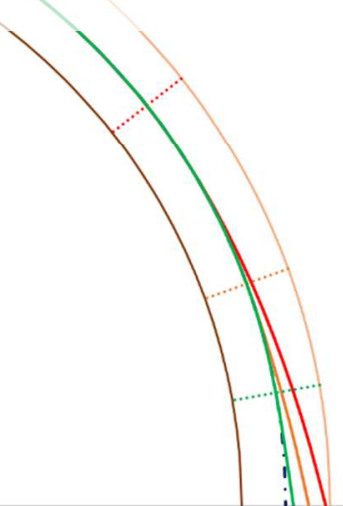

FiguTable re 11: Meridional section of the general thrust surface of the dome of Gol Gumbaz for different crack lengths, the thrust surface eccentricity. $\left(R=22,1 \mathrm{~m}, t=300 \mathrm{~cm}, w=60 \frac{\mathrm{kN}}{\mathrm{m}^{2}}\right)$ 
Table 1: Calculated data of the dome of Gol Gumbaz, India for existing crack lengths

\begin{tabular}{|c|c|c|c|c|c|c||c|c|}
\hline \multirow{2}{*}{$\begin{array}{c}\text { Crack } \\
\text { position } \\
\varphi^{\circ}\end{array}$} & $e, \mathrm{~m}$ & $\begin{array}{c}N_{\varphi,} \\
\mathrm{kN} / \mathrm{m}\end{array}$ & $\begin{array}{c}Q_{\varphi,}, \\
\mathrm{kN} / \mathrm{m}\end{array}$ & $\begin{array}{c}\sigma_{\max }, \\
\mathrm{kN} / \mathrm{m}^{2}\end{array}$ & $\begin{array}{c}\sigma_{\min }, \\
\mathrm{kN} / \mathrm{m}^{2}\end{array}$ & $\begin{array}{c}\text { Crack in } \\
\text { hoop } \\
\text { direction? }\end{array}$ & $\begin{array}{c}f_{\mathrm{c}, \text { req, }} \\
\mathrm{kN} / \mathrm{m}^{2}\end{array}$ & $\begin{array}{c}f_{\mathrm{v}, \text { req, }} \\
\mathrm{kN} / \mathrm{m}^{2}\end{array}$ \\
\hline 70 & 0,783 & 1326 & 317,5 & 1233,2 & 0 & yes & 924,9 & 147,7 \\
\hline 80 & 0,264 & 1326 & 193,2 & 778,5 & 314,6 & no & 536,2 & 64,4 \\
\hline
\end{tabular}

\section{CONCLUSIONS}

The paper examined the equilibrium of a masonry dome, loaded by its self-weight, in a natural, cracked state. The cracks are meridional through cracks. The cap of the dome was modelled as a membrane shell while the cracked bottom part was considered as a bending shell with a special internal force system related to the meridional cracks. Both parts are statically determinate in that sense that the equilibrium equations alone determine the internal force system. The two solutions were jointed at the end of the meridional cracks.

The internal force system of the cracked dome defines the thrust surface which could be used to examine the safety of the cracked dome.

Three kind of, stereotomy influenced, thrust surfaces may be distinguished: catenary-type, funicular-type and general thrust surface. The paper considers only radial type stereotomy.

Based on the numerical example the following conclusion may be drawn:

- Masonry dome has safe equilibrium state when it is cracked and it may be checked using the thrust surface of the dome,

- The tensile strength of the masonry dome material and the crack length influences or determines the possible, safe equilibrium state,

- $\quad$ It is suspected, based on the suggested model, that there is a possibility of unstable crack propagation in order to reach a safe equilibrium state,

- It seems, that there is no possibility of collapse of the dome for self-weight if the possibility of crack propagation is considered.

The examination of the long term cracked dome of Gol Gumbaz, Bijampur, India gave result corresponding to the more than 300 years of experience. This shows the effectiveness of the proposed simple model.

Finally, the main conclusion could be that the crack propagation process must be considered in order to develop a more precise masonry dome model.

Acknowledgements. The research was supported by the NKFIH Grant 124859 and the FIKP grant of EMMI in the frame of BME FIKP-VÍZ. 


\section{REFERENCES}

[1] J. Heyman On the shell solution of masonry domes. Int. J. of Solids Structures (1967) 3:227-241.

[2] ed. S Adriaenssens et.al. Shell structures for architecture. Form finding and optimization. Routledge, (2014).

[3] F. Fraternali A thrust network approach to the equilibrium problem of unreinforced masonry vaults via polyhedral stress functions. Mech. Res. Comm. 37, pp. 198-204 (2010).

[4] A. Baratta, O. Corbi On the statics of no-tension masonry-like vaultas and shells: solution domains, operative treatment and numerical validation", Ann. of Solid and Struct. Mech. (2011) 2:2-4:107-122.

[5] O. Gáspár, A. A. Sipos and I. Sajtos Effect of stereotomy on the lower bound value of minimum thickness of semi-circular masonry arches Int. J. of Arch. Her. (2018) 12:6:899921.

[6] I. Sajtos, O. Gáspár, A. Á. Sipos Geomery of the crack-free spherical masonry dome. In: C. Lázaro et. al. (eds.) Form and Force. Proc. of the $60^{\text {th }}$ Anniversary Symposyum of IASS. CIMNE, Barcelon, Spain (2019), pp.1450-1457.

[7] R. Mark, P. Hucthinson On the structure of the roman Pantheon. The Art Bulletin (1986) 68:1:24-34.

[8] W. Flügge Stresses in shells. Springer-Verlag, Berlin, (1960).

[9] P. Csonka Theory and practice of membrane shells. Akadémiai Kiadó, Budapest, (1987).

[10] P. L. Gould Analysis of plates and shells. Prentice Hall, (1999).

[11] Block, P., \& Ochsendorf, J. Thrust network analysis: a new methodology for threedimensional equilibrium. Journal of the International Association for Shell and Spatial Structures, (2007) 48:3:167-173.

[12] Block, P. Thrust Network Analysis: Exploring Three-dimensional Equilibrium. PhD dissertation, Massachusetts Institute of Technology. Cambridge, USA., (2009).

[13] M. Varma et. al. Stability of masonry dome: Special emphasis on 'Golagumbaz'. In: P.B. Lourenco et. al. (eds.) Structural Analysis of Historical Constructions. Possibilities of Numerical and Experimental Techniques. Proc. of the $5^{\text {th }}$ Int. Conf. on Structural Analysis of Historical Constructions, New Delhi, India (2006), pp.1789-1794. 